\title{
Correction to: Synthesis of anisotropic rod-like gold nanostructures in organic media
}

\author{
BHAGAVATULA L V PRASAD ${ }^{\mathrm{a}, \mathrm{c}, *}$ (1) , PRATHAP CHANDRAN SIVASANKARAN ${ }^{\mathrm{a}, \mathrm{c}}$, \\ PITAMBAR PATEL ${ }^{\mathrm{b}, \mathrm{c}}$, PUSHPA V MALEKAR ${ }^{\mathrm{b}, \mathrm{c}}, \mathrm{K}^{\mathrm{V}} \mathrm{MAYA}^{\mathrm{a}, \mathrm{c}}$ and \\ CHEPURI V RAMANA ${ }^{\mathrm{b}, \mathrm{c}, *}$ \\ ${ }^{a}$ Physical and Materials Chemistry Division, CSIR-National Chemical Laboratory, Dr. Homi Bhabha Road, \\ Pune 411 008, India \\ ${ }^{b}$ Organic Chemistry Division, CSIR-National Chemical Laboratory, Dr. Homi Bhabha Road, Pune 411008 , \\ India \\ ${ }^{c}$ Academy of Scientific and Innovative Research (AcSIR), Ghaziabad 201 002, India \\ E-mail: pl.bhagavatula@ncl.res.in; vr.chepuri@ncl.res.in
}

Correction to: J. Chem. Sci. (2021) 133:106

https://doi.org/10.1007/s12039-021-01952-z

The wrong Supplementary file was originally published with this article; it has now been replaced with the correct file.

The original article has been corrected.

*For correspondence

Supplementary Information: The online version contains supplementary material available at https:// doi.org/10.1007/s12039-021-01992-5. 